\title{
A Review on the Methods of Speed Control of Brushless D.C. Motor - A Comparative Study
}

\author{
Devendra Gowda ${ }^{1}$, Pratik Dharme $^{2}$, Sanjeev Todkar ${ }^{3}$, Chandan Desai $^{4}$, Tejas Patil ${ }^{5}$, Sushant Khot ${ }^{6}$ \\ ${ }^{1}$ Assistant Professor, Department of Electrical Engineering, DKTE's Society Textile and Engineering College, \\ Ichalkaranji, India \\ 2,3,4,5,6UG Student, Department of Electrical Engineering, Sanjay Ghodawat Institutes, Kolhapur, India \\ *Corresponding author: chandandesai157@gmail.com
}

\begin{abstract}
In this paper detailed working of BLDC motor is shown. BLDC motor has many applications, hence there are various methods of their control, these various methods of speed control are explained below. General methods like PI, PID don't have expected results for control of speed. Fuzzy control and neuro-fuzzy control system give far better output than these methods. In this paper we analyze the speed output with different method.
\end{abstract}

Keywords: BLDC, Efficiency, Motors, Power, Speed control.

\section{Introduction}

BLDC motor is extensively used in different type of applications like industrial, household equipment's, electronic equipment's, etc. It is favorable as compared to other motors like dc motors and induction motor. As the name suggests, the motor does not have brushes for the process of commutation. It does require electronic switches. As compared to other motors it has better speed torque characteristics. The motor requires sensing elements to sense the rotor position inside the motor. For this purpose, we use hall effect sensors. The motor has long operating life, noiseless operating, high efficiency and greater dynamic response.

\section{A. Stator}

It consists of steel laminations in stacked form. The windings of rotor are connected in star phase. The coils are placed in the slots and they are interconnected to make the winding.

\section{B. Rotor}

The rotor of BLDC motor consists of permanent magnet which can be from two poles to eight poles setup with north and south poles. The permanent magnets used are ferrite magnets. The placement of hall sensor is as shown below,

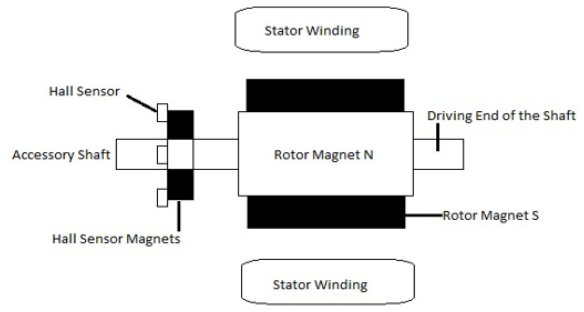

Fig. 1. Placement of hall effect with respect to rotor

\section{Operation of Motor}

Brushless dc motor defined is also known as permanent magnet synchronous motor. This motor is mostly controlled by three phase semiconductor bridge. This motor operates in six states and every state two phase have similar working. The operating circuit of BLDC is shown below.

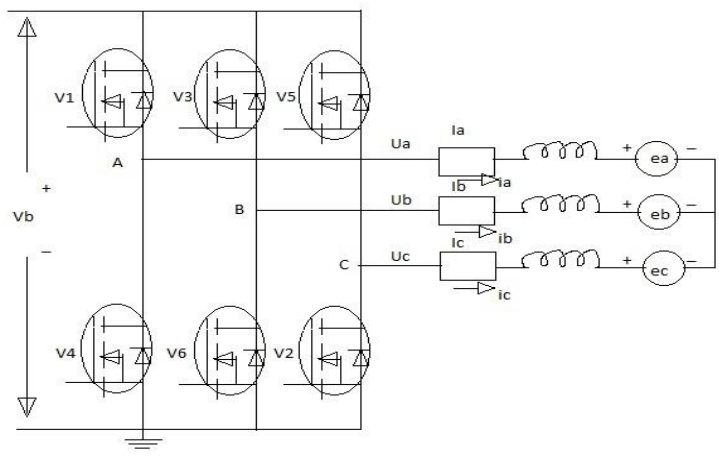

Fig. 2. Circuit of motor

As shown in the circuit three phase VSI system is connected to the rotor of BLDC motor and also hall effect sensor is also used for sensing rotor position, where the resistances connected are denoted by $R_{a}, R_{b}, R_{c}$ and $L_{a}, L_{b}, L_{c}$ are the inductances of the phases.

The commutation sequence with respect to rotor position is shown below,
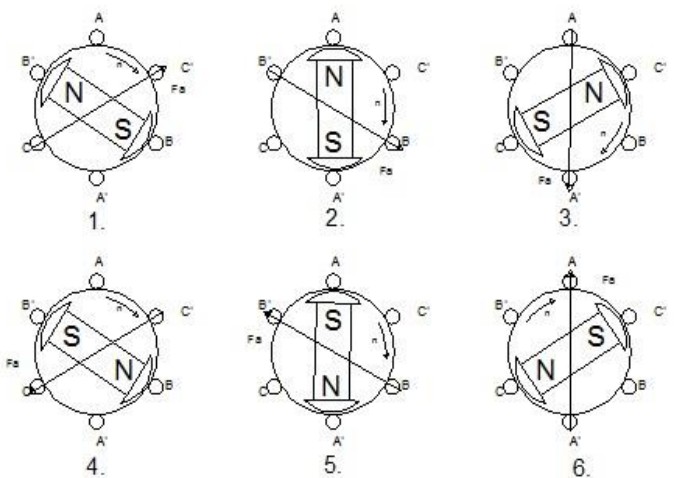

Fig. 3. Rotor position 
Volume-3, Issue-9, September-2020

\section{IJRESM journals.resaim.com/ijresm | ISSN (Online): 2581-5792 | RESAIM Publishing}

The MOSFETS'S connected work in a conducting sequence hence the magnetic field generated by the stator applies magnetic force on the rotor. The arrows shown in the diagram show the direction of magnetic field.

The waveform below is the back emf waveform of the motor, wherein the emf for every phase are shown.

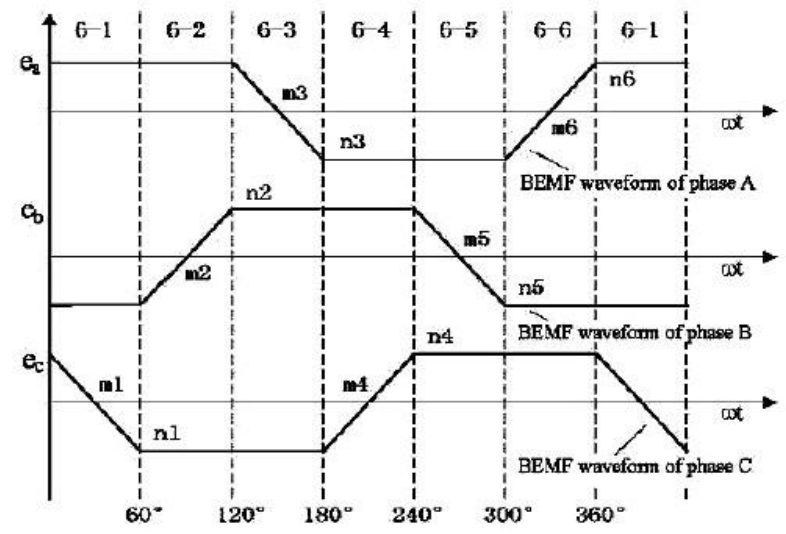

Fig. 4. Back emf

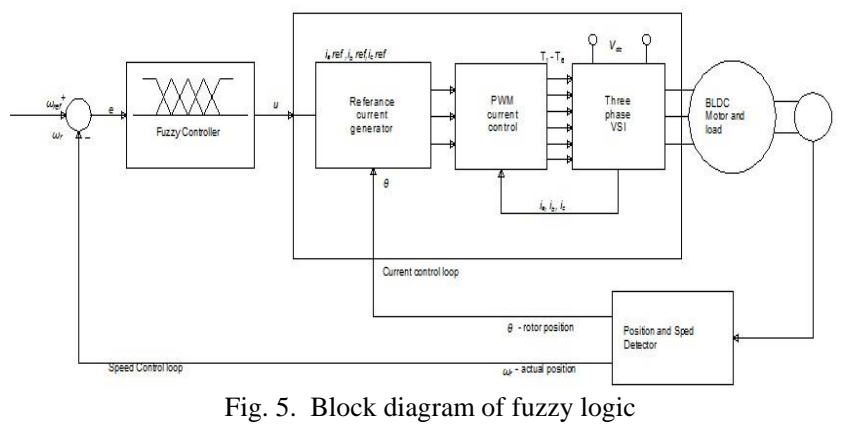

The diagram below is of the fuzzy logic applied for speed control. As shown in the diagram the first loop is speed control loop whereas the second loop is current control loop. The input to the BLDC motor is fed through inverter and also the reference speed is compared to actual speed in the loop.

\section{Mathematical Representation}

The mathematical representation of the motor is as follows,

$$
\begin{aligned}
{\left[\begin{array}{l}
u a \\
u b \\
u c
\end{array}\right]=\left[\begin{array}{lll}
R & 0 & 0 \\
0 & R & 0 \\
0 & 0 & R
\end{array}\right] \times\left[\begin{array}{l}
i a \\
i b \\
i c
\end{array}\right] } & \\
& +\left[\begin{array}{ccc}
L_{m}-M & 0 & 0 \\
0 & L_{m}-M & 0 \\
0 & 0 & L_{m}-M
\end{array}\right] \frac{d}{d t}\left[\begin{array}{c}
i a \\
i b \\
i c
\end{array}\right] \\
& +\left[\begin{array}{l}
e a \\
e b \\
e c
\end{array}\right]
\end{aligned}
$$

Here, $\mathrm{R}$ and $\mathrm{M}$ is the resistance and mutual inductance of the given stator, whereas $u_{a}, u_{b}, u_{c}$ are the phase voltage and $i_{a}, i_{b}, i_{c}$ are the phase current and $e_{a}, e_{b}, e_{c}$ are the back emf voltage of the stator.

Electromagnetic torque is given by,

$$
T e=\frac{Z_{p}}{2 \omega_{e}}\left(e_{a} i_{a}+e_{b} i_{b}+e_{c} i_{c}\right)
$$

Here $\omega_{e}$ and $Z_{P}$ are the electrical speed and number of magnetic poles.

The equation for the motion can be expressed as,

$$
T_{e}=T_{L}+J \frac{d \omega_{r}}{d t}+B \omega_{r}
$$

Here, $T_{L}$ is load torque, $\omega_{r}$ is angular velocity, $\mathrm{J}$ is inertia, B is friction constant.

The expression for motion equation is given by,

$$
\begin{gathered}
\frac{d \omega_{m}}{d t}=\left(\frac{P}{2 J}\right)\left(T_{e}-T_{L}-B \omega_{r}\right) \\
\text { and } \frac{d \theta}{d t}=\omega_{r}
\end{gathered}
$$

$\omega_{m}$ and $\omega_{r}$ are used to denote rotor speed in mechanical $\mathrm{rad} / \mathrm{s}$ and electrical rad/s respectively.

Expression for trapezoidal back-emf,

$$
\left(\begin{array}{l}
e a \\
e b \\
e c
\end{array}\right)=E\left[\begin{array}{l}
f a(\theta) \\
f b(\theta) \\
f c(\theta)
\end{array}\right],\left(E=K_{e} \omega_{r}\right)
$$

$\mathrm{K}_{\mathrm{e}}$ denotes back emf constant, $f a(\theta), f b(\theta), f c(\theta)$ are functions of rotor position.

\section{Resultant Speed of Motor for Various Methods}

Speed control of motor by various methods is shown below,

\section{A. Using PI Controller}

By using MATLAB simulation the below waveform is obtained for the speed control using pi controller,

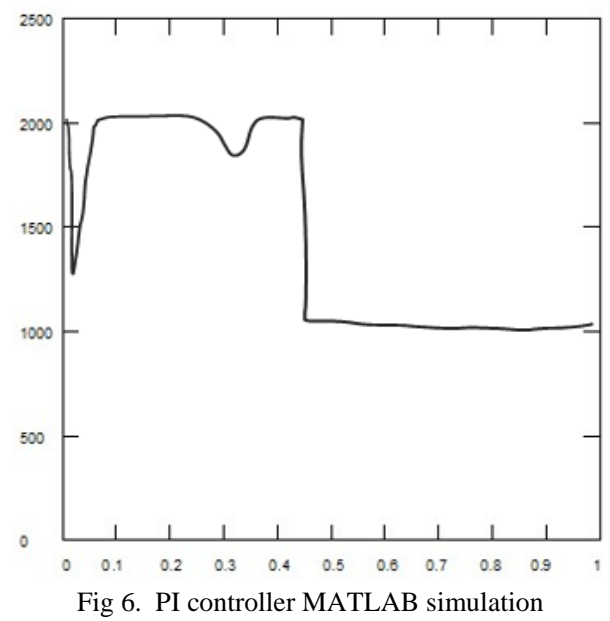


Volume-3, Issue-9, September-2020

\section{IJRESM journals.resaim.com/ijresm | ISSN (Online): 2581-5792 | RESAIM Publishing}

As shown in the diagram overshoot is shown, hence we linear graph for speed could not be obtained. Due to this reasons this method is not currently used.

\section{B. PID Controller}

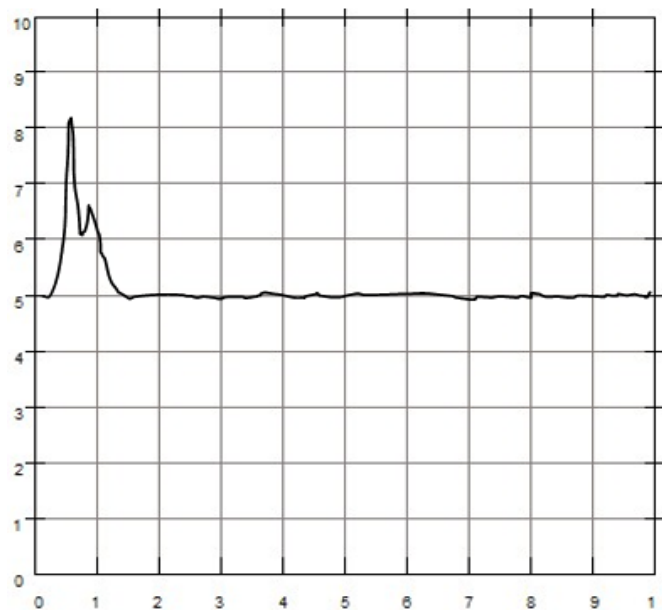

Fig. 7. Speed control using PID

When PID control is used the program required for control is complicated since it requires a special algorithm to overcome the removal of current sensor. This causes reduction in accuracy of speed result.

\section{Fuzzy logic controller}

The diagram shows the speed control using fuzzy logic controller. There is a small overshoot at the starting. After the overshoot we get a linear graph. This graph shows the linear control and good result as compared to above methods.

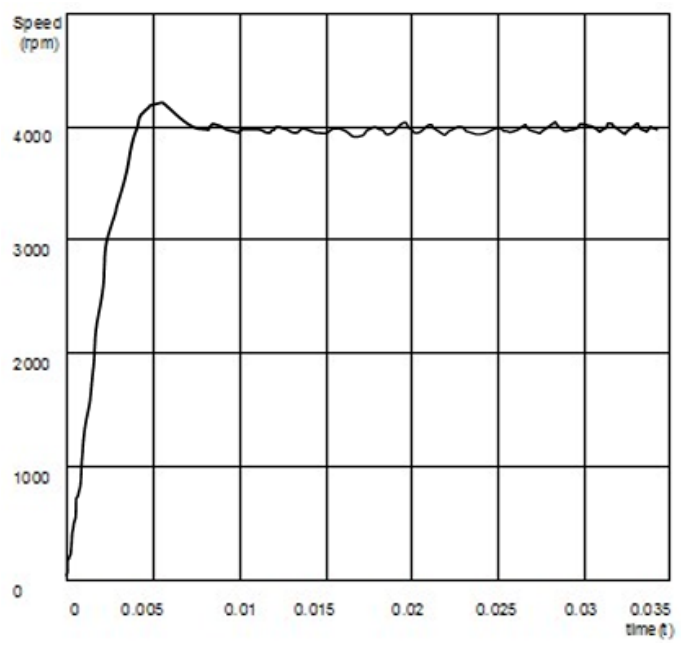

Fig. 8. Fuzzy logic control

\section{Neuro- Fuzzy Control}

The waveform shown is of neuro-fuzzy controller. As shown in the waveform this method has a lower overshoot and also requires less settling time, hence overall gives a better control than above methods.

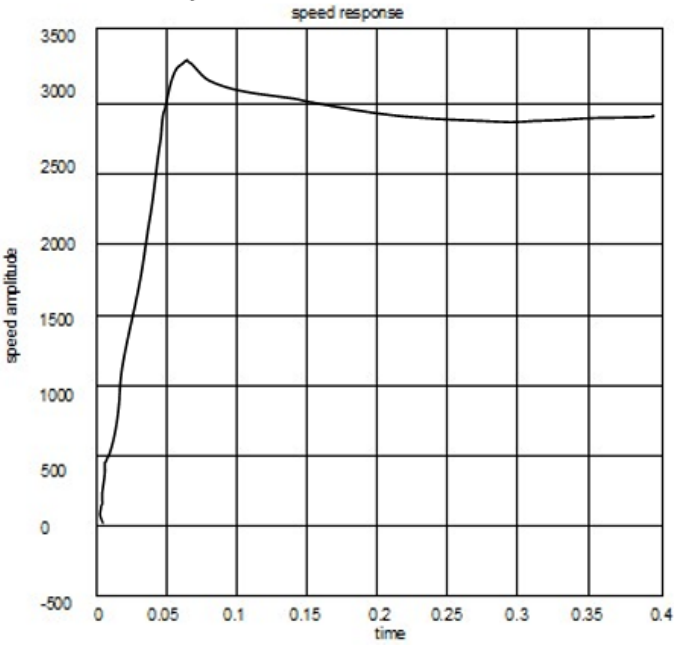

Fig. 9. Neuro-Fuzzy Control

\section{Conclusion}

From this paper we can conclude that the application of Neuro Fuzzy controller gives much better control as compared with the PI, PID and Fuzzy Controller. Also this method provides better speed response and lower overshoot, so it is used for many non-linear systems. This method is mostly used for controlling purpose because this is a combination of neural and fuzzy logic.

\section{References}

[1] S. Rambabu, "Modelling and control of brushless de motor" master of technology in power control and drives," Thesis, Department of electrical engineering, National institute of technology, Rourkela, 2007.

[2] M. V. Ramesh, J. Amarnath, S. Kamakshaiah and G. S. Rao, "Speed control of brushless dc motor using fuzzy logic pi controller," ARPN Journal of Engineering and Applied Sciences, vol. 6, no. 9, September 2011

[3] M. Vignesh Kumar, "Speed control of three phase BLDC motor using four switch inverters," in International journal of scientific Engineering research, vol. 4, no. 5, May 2013.

[4] Mehmet Cunkas, Omer Aydogdu, "Realization of fuzzy logic controlled brushless dc motor drives using MATLAB/Simulink," in Mathematical and Computational Applications, vol. 15, no. 2, pp. 218-229, 2010. 